\title{
Cruzamentos lexicais no discurso literário
}

\author{
Elis de Almeida Cardoso*
}

RESUMO: O presente trabalho tem o objetivo de analisar, no discurso literário, quais os efeitos de sentido obtidos com os cruzamentos lexicais. Após a definição desse processo de formação de palavras, em que se verifica uma união morfofonológica impulsionada e motivada pelo resultado semântico, pretende-se mostrar que o significado da nova formação está associado não só a questões culturais e comportamentais, como também à expressão do sentimento.

PALAVRAS-CHAVE: Cruzamento lexical; expressividade; discurso literário.

\section{Introdução}

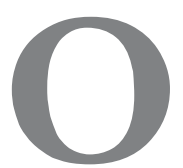

s cruzamentos vocabulares (Sandmann, 1990) ou lexicais, também chamados de amálgamas (Pruvost-Sablayrolles, 2003), palavras-valise (Alves, 1990), palavras portmanteau na acepção de Lewis Carroll (Cf. Martins, 1997, p. 123), e mais recentemente de blends e mesclagens lexicais (Gonçalves, 2006), são formados pela união entre dois vocábulos com um objetivo específico e um significado próprio.

Segundo Martins: "A sua formação revela criatividade, espírito, e sua força expressiva resulta da síntese de significados e do inesperado da combinação" (1997, p. 123-124).

Dificilmente os cruzamentos são estudados como um processo de formação de palavras e, algumas vezes, são confundidos e analisados como se fossem um caso de composição por aglutinação.

Trata-se, entretanto, de um processo diferente em que unidades lexicais se mesclam formando outra unidade, sem, entretanto, manterem, obrigatoriamente seus radicais. Há casos em que se mantém a parte inicial de uma unidade e a parte final de outra (portunhol), há casos em que uma unidade mantém

* Universidade de São Paulo-elisdacar@. 


\section{CARDOSO, Elis de Almeida. Cruzamentos lexicais no discurso literário}

sua integridade morfofonológica e a outra sofre uma ruptura (showmício), e há casos em que uma unidade adentra-se na outra (chafé, lixeratura, namorido), havendo entre elas uma interseção lexical.

Nesse processo ocorre, portanto, mais do que uma aglutinação, uma união morfofonológica impulsionada e motivada pelo resultado semântico. "Mesclas são caracterizadas pela interseção de palavras, de modo que é impossível recuperar, através de processos fonológicos como crase, elisão e haplologia, as seqüências perdidas" (Gonçalves, 2006, p. 220).

O significado da nova formação está associado a várias questões culturais e comportamentais. Voláteis ou nem tanto, na grande maioria das vezes elas refletem a visão crítica e o humor gerado por um momento específico. Algumas entram na língua e deixam de ser percebidas como uma espécie de brincadeira lingüística (motel [motor + hotel]), outras se resumem a um momento associado a um fato político (Bill Pinton [Bill Clinton + pinto], Martaxa [Marta + taxa]), a uma personagem de novela ou programa de televisão (Peiticeira [peito + Feiticeira], Lucianta Gimenez [Luciana + anta]), a um acontecimento explorado pela mídia (Febemdiru [Febem + Carandiru]).

\section{Cruzamentos vocabulares e uso na língua}

Por não revelar tanta produtividade, como outros processos, as mesclas são vistas por muitos autores como processos marginais. A atenção a esse processo deve se voltar principalmente para a criatividade lexical, uma vez que se chama a atenção justamente para o inesperado resultante da combinação sintética.

Em alguns casos, entretanto, ficam tão usuais que entram na língua, deixando até de ser percebidos como cruzamentos. É o que acontece, por exemplo, com motel, nome dado a estabelecimentos que alugam quartos por curtos períodos para encontros amorosos. Originalmente o motel, resultado do cruzamento entre motor e hotel (do inglês), é um "hotel com estacionamento para veículos motorizados, em que se tem acesso aos quartos diretamente da área em que ficam os veículos" (Houaiss).

Há algum tempo um novo esporte, o futevôlei, invadiu as praias brasileiras. Trata-se de um jogo parecido com o vôlei em que os jogadores utilizam no lugar das mãos, os pés e a cabeça, assemelhando-se ao futebol. O Houaiss registra o termo, que, por fazer porte do universo desportivo, deixa de ser expressivo.

São também dicionarizadas pelo Houaiss formas como portunbol- "português mesclado com palavras e elementos fonéticos do espanhol ou preten- 
samente do espanhol, us. por falantes de português na sua comunicação com hispanófonos, ou vice-versa" -, sacolé - "espécie de sorvete feito de água e xarope ou sumo de fruta, que se congela dentro de um saquinho plástico, produzindo um picolé sem pauzinho", dentre outros,

Já os cruzamentos não dicionarizados têm enorme força expressiva pelo fato de traduzirem o ponto de vista do emissor e podem ser encontrados além da língua comum, na linguagem publicitária, nos textos e crônicas de humor e também nos textos literários.

Quando Mia Couto intitula seu livro de Estórias abensonhadas, está manifestando o seu ponto de vista e sua visão sobre as estórias que falam sobre a possibilidade de refazer a vida e de sonhar, escritas depois da guerra em Moçambique.

A expressão da pejoratividade também encontra um vale fértil nas mesclas. A intenção depreciativa é, pois, verificada facilmente em cruzamentos como secretina (secretária + cretina) ou professorror (professor + horror). Em intelijumento (inteligente + jumento), percebe-se a ironia, resultante da expressão: tão inteligente quanto um jumento.

\section{A formação dos cruzamentos}

Pode-se dizer que há basicamente dois processos de formação dos cruzamentos vocabulares: por interseção de uma unidade em outra e por truncamento de uma ou das duas unidades componentes.

Para que haja a interseção de uma unidade em outra é preciso haver entre as unidades uma correspondência fonológica, responsável pela soldagem que pode ser maior ou menor, dependendo do caso.

Em lixeratura (lixo e literatura), em chafé, (chá e café) e em namorido (namorado e marido), as interposições podem ser representadas pelos esquemas abaixo:

LIX $(\mathrm{O})$

LI(T)ERATURA

LIXERATURA

CHÁ

C AFÉ

CHAFÉ 


\author{
NAMOR(A)DO \\ $\mathrm{M}(\mathrm{A}) \mathrm{RIDO}$ \\ NAMORIDO
}

Os casos mais expressivos são os formados pelas interseções, uma vez que a perda de fonemas de cada uma das bases formantes é mínima ou nula. A expressividade, entretanto, não advém apenas do imprevisto e da perfeição da fusão, mas principalmente pelo fato de o resultado revelar aspectos sociais e culturais. O bom café é um café forte e preto, coado com quantidade razoável de pó e pouca água. O café fraco, com muita água e pouco pó, é considerado ruim. Por assemelhar-se ao chá na cor e na quantidade de água, o café fraco e ruim passou a ser chamado de chafé.

Morar com o namorado e viver com ele na condição de marido passou a ser algo muito comum de alguns anos para cá. O namorido é mais do que namorado, uma vez que com ele se compartilha a casa e não é considerado marido, uma vez que não há comprometimento com a estabilidade da relação. Por ora só há na língua a versão masculina. A versão feminina namoradaesposa não apresenta fonemas e morfemas comuns para a fusão, não satisfazendo, dessa forma, condições para a formação.

Como exemplos de cruzamentos provenientes do truncamento de uma das bases ou das duas citam-se portunhol, chocolícia, showmicio, representados pelos esquemas a seguir:

\title{
PORTU(GUÊS) \\ (ESPA)NHOL \\ PORTUNHOL
}

CHOCOL(ATE)

(DE)LÍCIA

CHOCOLÍCIA

SHOW

(CO)MíCIO

SHOWMÍCIO 
Nesse tipo de cruzamento, o compartilhamento do material fonológico é bem mais tênue do que no primeiro caso.

Parece que o volume da palavra é responsável pelo truncamento ou não. Palavras com volume parecido (português e espanhol) sofrem ambas o truncamento. Em combinações de palavras com volumes diferentes, apenas a de volume maior sofre truncamento (show e comício).

Seja por interseção, seja por truncamento, nos dois tipos de mescla, há duas palavras que se unem, sendo que parte de uma completa o sentido da outra, ou de parte da outra.

As formações analógicas devem ser consideradas como um processo diferente do cruzamento vocabular. Nesses casos (bebemorar, boadrasta) não são duas palavras que se unem e se completam. Há um aproveitamento de um suposto significado de um segmento fonético e uma substituição por outro significado.

Na palavra comemorar encontra-se o segmento fonológico come-, coincidente com a forma do verbo comer. A partir daí, há uma desagregação vocabular come + morar e uma substituição da primeira parte analogicamente por bebe-, formando-se bebemorar. $\mathrm{Na}$ analogia está claramente contida a idéia de que a comemoração será marcada pelo consumo de bebida alcóolica.

O mesmo processo ocorre com boadrasta. A palavra madrasta sofre uma desagregação má + drasta e a parte inicial é substituída por boa, formando-se boadrasta. A analogia surge para se tentar desfazer a visão cultural, proveniente principalmente dos contos de fadas, de que toda madrasta é má.

$$
\begin{aligned}
& \text { COMEMORAR }-(\text { COME })+(\text { BEBE })=\text { BEBEMORAR } \\
& \text { MADRASTA }-(\text { MÁ })+(\text { BOA })=\text { BOADRASTA }
\end{aligned}
$$

O cruzamento ou mesclagem lexical é, portanto, um processo de formação de palavras em que pelo menos duas palavras se unem. Essa união, resultado de uma combinação morfofonológica produz um resultado inusitado e, por isso, expressivo.

\section{Cruzamentos lexicais no texto literário}

Autores que são criadores lexicais como Guimarães Rosa, Oswald de Andrade, Haroldo de Campos e Carlos Drummond de Andrade utilizam em seus textos mesclas lexicais que funcionam como unidades discursivas responsáveis por traduzir a expressão do sentimento. 
Mais do que estudados apenas pelo processo responsável por sua formação, os cruzamentos lexicais literários devem ser analisados discursivamente, levando-se em conta seu potencial de expressividade e o significado que apresentam no contexto em que se inserem.

De Guimarães Rosa, analisa-se a formação embriagatinhar: "E, desistindo do elevador, embriagatinhava escada acima." (Rosa, 1979, p. 104).

Ao formar o verbo embriagatinhar [embriagar + engatinhar ou gatinhar], Guimarães Rosa consegue expor ao leitor todo o efeito do bêbado que, por não conseguir se equilibrar apenas nas duas pernas, necessita também do apoio dos braços, por isso engatinha. Ao engatinhar ou andar de quatro, o homem assemelha-se a uma criança que ainda não tem razão ou ainda a um gato ou a qualquer outro animal. $\mathrm{O}$ embriagado, pois, animaliza-se, não conseguindo sequer realizar um ato tão simples quanto apertar o botão do elevador.

A sílaba comum ga faz a união fônica entre as bases que se interseccionam. Tomando-se a união entre embriagar e engatinhar, a sílaba inicial em(n) é comum aos dois verbos, o que reforça a fusão.

Das várias mesclas encontradas na obra de Oswald de Andrade, cita-se aqui a formação do verbo monotocar: "Célia monotocava shimmys e Mozart no piano bandolim da sala de jantar entre paisagens iguais das janelas." (Andrade, 2001, p. 71).

Ao formar monotocar [monótono ou monotonamente + tocar], Oswald de Andrade mostra ao leitor que aquela música tocada ao piano por Célia era repetida, invariável e, pela ausência de novidade, maçante e enfadonha, como as paisagens "iguais" das janelas.

A sílaba to faz a junção entre monotonamente e tocar. Para haver a perfeita união e o resultado pretendido, o advérbio antecede o verbo. Não se trata aqui de uma junção do elemento mon(o) - e do verbo tocar. O sentido que o autor quer dar ao contexto é o da monotonia e é o que se obtém com a interseção.

Grande criador lexical, Haroldo de Campos, em Galáxias, refere-se às "velhas senhoras de chapéus de cogumelos" como coguvelhas.

"velhas senhoras de chapéus de cogumelos tortulhos em conciliábulo chuchando chá tee mit zitronensaft a água se avinhando nas taças vermelhando saquinhos de chá moídos pendendo de fios à beira das chávenas tudo previsto para o pacífico parlamento de cogumelos velhas velhas gordas velhíssimas meiovelhas envelhando semiengelhando gelhando magras velhas gordando coguvelhas gustando tortas de maçã apfelkuchen ...” (Campos, 2004, p. 6).

O encontro das senhoras que juntas tomam chá e conversam é vislumbrado pelo autor como um "conciliábulo" de velhas que portam chapéus de 
cogumelos e se transformam em verdadeiros cogumelos, em fungos idosos, em mofos.

Não há entre cogumelo e velha qualquer sílaba comum. Apenas a liquidez do /h/ de velha e do /l/ de cogumelo aproximam-se. A truncação de cogu(melo) e a junção com velha(s) faz do cruzamento uma palavra tão estranha como aquelas mulheres enrugadas, murchas e magras.

Carlos Drummond de Andrade faz uso de várias mesclas em Ao deus Kom Unik Assão, poema que abre o livro As impurezas do branco (Andrade, 2002, p. 705-8). Trata-se de uma crítica severa à massificação, à sociedade de consumo, ao homem-robô que não age mais por conta própria e que, por isso, pode ser comparado a um animal, a um ser não-pensante.

$\mathrm{O}$ autor cria os verbos adourar, amourar e sonourar - introduzindo em adorar, amare * sonorar o substantivo ouro, reforçando a importância material do deus. O enunciador adora, ama o ouro, além de escutar o som do ouro emanado pelo deus.

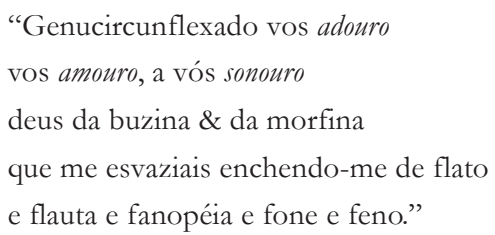

A animalização e irracionalidade daqueles que acreditam no deus e o seguem pode ser percebida ao longo do texto. No fragmento "aspirava a ser eumano", percebe-se que em eumano existe uma junção de eu + bumano e um jogo com a palavra ser. Na verdade, o poeta aspirava a ser um ser humano e também aspirava a encontrar seu próprio eu, daí eumano.

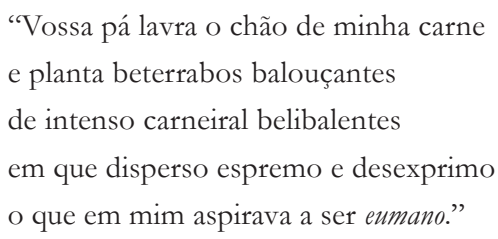

A inutilidade, o blá-blá-blá, a conversa que não serve para nada, o finrinfinfim estão cada vez mais próximos. A ironia evidencia-se no momento em que se vê a saudação à "plurimelodia distriburrida no planeta". Com a criação de distriburrida, o autor está mesclando a forma participial distribuída com o adjetivo burro, ou seja, ao espalhar suas melodias pelo planeta, o deus faz com que as pessoas emburreçam. 


\author{
"Salve, meio-fim \\ de finrinfinfim \\ plurimelodia \\ distriburrida no planeta."
}

A goela das pessoas está mais do que escancarada, está escãocarada, como afirma o poeta. A junção de escancarada e cão reforça a idéia de animalidade e mostra que todos estão completamente abertos e engolem de forma natural e insaciável qualquer coisa que seja apresentada. O mesmo se percebe com a formação de komunikão [komunikar + cão].

Por mais fartos que todos estejam desse massacre, querem pisaduras mais. Com a criação do substantivo pisaduras, o poeta faz um jogo com a sufixação pisada + -dura e com o cruzamento pisada + dura.

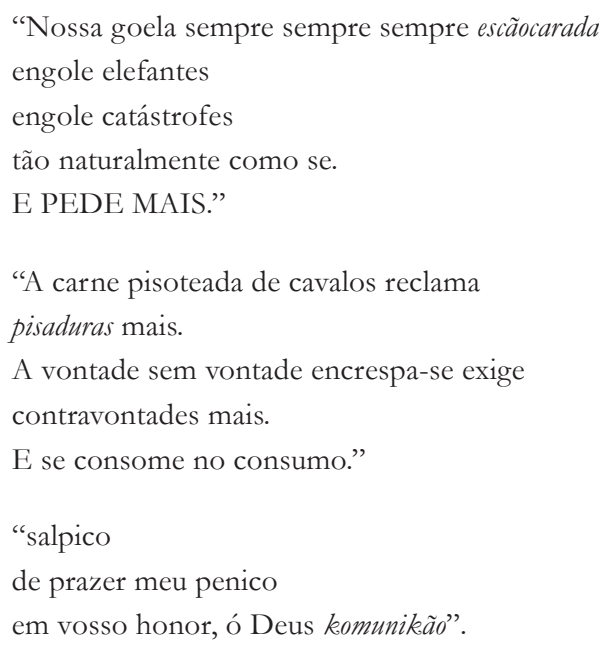

Se, por um lado, o deus Kom Unik Assão animaliza as pessoas, por outro ele é necessário. Se a comunicação não atinge a todos, há necessidade que atinja. Surge, então, uma ânsia pela comunicação, uma komunikânsia.

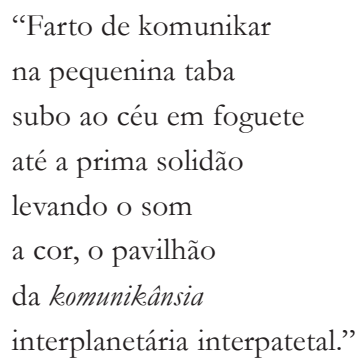




\section{Considerações finais}

Tomando como base a definição de estilo de Guiraud (1975, p. 7), podese afirmar que por trás de uma escolha existe sempre uma intenção e, dependendo de sua intenção, o enunciador do discurso pode criar um ou outro efeito de sentido.

Por meio da escolha das palavras é possível, então, perceber não só a visão de mundo do enunciador como também outros elementos da situação da enunciação tais como tempo, lugar, etc. Para Brait (1994-5, p. 26), a análise dos elementos persuasivos do discurso - e é claro que as criações lexicais merecem um devido destaque - deve levar em conta "os traços que permitem reconhecer uma certa intenção do enunciador, os efeitos de sentido visados pelo texto, pelo discurso produzido por esse enunciador e pelo locutor ou locutores por ele instituídos, e a manipulação que o enunciador pretende exercer sobre aquele a que o discurso se destina".

Os cruzamentos lexicais, não só do uso comum, mas também os encontrados no discurso literário revelam toda a criatividade lexical, ou seja, a "capacidade que o falante possui para alargar o sistema lingüístico, de forma consciente, por meio de princípios de abstração e comparação imprevisíveis, mas motivados" (Correia, 2003).

Embora considerado um processo de formação de palavras "marginal", as mesclas têm sua função e podem ser sistematizadas e estudadas como um processo diferente da composição. Sua principal função, ao se manifestarem no discurso concretamente realizado, é mostrar que o enunciador é capaz de revelar seus conceitos internalizados e os efeitos de sentido que pretende apresentar, por meio da criação lexical.

\section{Bibliografia}

ALVES, I. M. (1990) Neologismo: criação lexical. São Paulo: Ática.

ANDRADE, C. D. de (2002) Poesia completa. Rio de Janeiro: Nova Aguilar.

ANDRADE, O. de (2001) Memórias sentimentais de João Miramar. 14 ed. São Paulo: Globo.

BASÍLIO, M. (1987) Teoria lexical. São Paulo: Ática.

BRAIT, B. (1994-5) A construção do sentido: um exemplo fotográfico persuasivo. Lingua e Literatura, 21. São Paulo: FFLCH/USP.

CAMPOS, H. de (2004) Galáxias. 2. ed. São Paulo: Editora 34.

CORREIA, M. (2003) Criatividade e inovação terminológica - novos desafios. Comunicação inédita apresentada ao Colóquio Internacional A neologia cientifica: balanço e perspectivas da Organização da União Latina, Roma. 
52 CARDOSO, Elis de Almeida. Cruzamentos lexicais no discurso literário

GONÇALVES, C. A. V. (2006) Usos morfológicos: os processos marginais de formação de palavras em português. Gragoatá, 21, p. 219-242.

GUIRAUD, P.; KUENTZ, P. (1975) La stilystique. Paris: Klincksieck.

PRUVOST, J.; SABAYROLLES, J.F. (2003) Les néologismes. Paris: PUF.

ROCHA, L. C. (1998) Estruturas morfológicas do português. Belo Horizonte: Ed. UFMG.

ROSA, J. G. (1979) Tutaméia. 5. ed. Rio de Janeiro: José Olympio.

SANDMANN, A. J. (1990) Morfologia lexical. São Paulo: Contexto.

ABSTRACT: The present paper has the objective to analyse, in the literary discourse, which the effects of sense obtained with the blends (mots-valise). After the definition of this process of formation of words, in which an union morphofonological driven and caused by the semantic result, intends to show that the meaning of the new formation is associated to cultural and behaviour questions and the expression of the feeling.

KEYWORDS: Blend; expressiveness; literary discourse. 